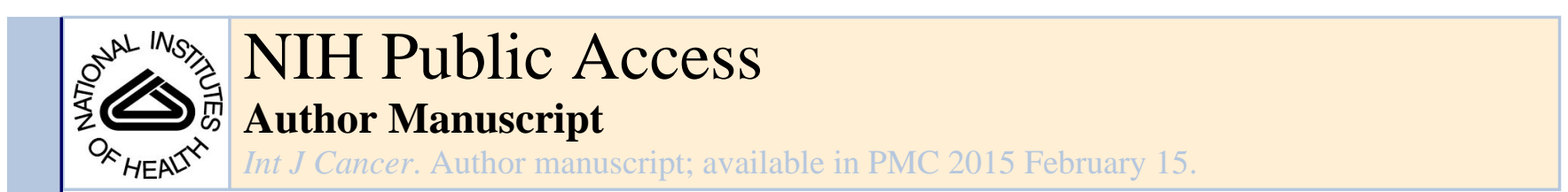

Published in final edited form as:

Int J Cancer. 2015 February 15; 136(3): 610-617. doi:10.1002/ijc.29016.

\title{
Vitamin E intake and the lung cancer risk among female nonsmokers: a report from the Shanghai Women's Health Study
}

\author{
Qi-Jun Wu, \\ State Key Laboratory of Oncogene and Related Genes, Shanghai Cancer Institute, Renji \\ Hospital, Shanghai Jiaotong University School of Medicine, Shanghai, China; Department of \\ Epidemiology, Shanghai Cancer Institute, Renji Hospital, Shanghai Jiaotong University School of \\ Medicine, Shanghai, China; Division of Epidemiology, Department of Medicine, Vanderbilt \\ Epidemiology Center, Vanderbilt-Ingram Cancer Center, Vanderbilt University School of \\ Medicine, Nashville, USA
}

\section{Yong-Bing Xiang,}

State Key Laboratory of Oncogene and Related Genes, Shanghai Cancer Institute, Renji Hospital, Shanghai Jiaotong University School of Medicine, Shanghai, China; Department of Epidemiology, Shanghai Cancer Institute, Renji Hospital, Shanghai Jiaotong University School of Medicine, Shanghai, China

\section{Gong Yang,}

Division of Epidemiology, Department of Medicine, Vanderbilt Epidemiology Center, VanderbiltIngram Cancer Center, Vanderbilt University School of Medicine, Nashville, USA

Hong-Lan Li,

State Key Laboratory of Oncogene and Related Genes, Shanghai Cancer Institute, Renji Hospital, Shanghai Jiaotong University School of Medicine, Shanghai, China; Department of Epidemiology, Shanghai Cancer Institute, Renji Hospital, Shanghai Jiaotong University School of Medicine, Shanghai, China

\section{Qing Lan,}

Division of Cancer Epidemiology and Genetics, National Cancer Institute, Rockville, USA

\section{Yu-Tang Gao,}

Department of Epidemiology, Shanghai Cancer Institute, Renji Hospital, Shanghai Jiaotong University School of Medicine, Shanghai, China

\section{Wei Zheng,}

Division of Epidemiology, Department of Medicine, Vanderbilt Epidemiology Center, VanderbiltIngram Cancer Center, Vanderbilt University School of Medicine, Nashville, USA

Xiao-Ou Shu, and

Division of Epidemiology, Department of Medicine, Vanderbilt Epidemiology Center, VanderbiltIngram Cancer Center, Vanderbilt University School of Medicine, Nashville, USA

Corresponding to: Jay H. Fowke, Ph.D., Vanderbilt Epidemiology Center, Vanderbilt University School of Medicine, Address: 2525 West End Ave., 12th Floor, Suite 1200, Vanderbilt University Medical Center, Nashville, TN37203-1738, United States, Phone: +1 615936 2903, Fax: 615-825-2655, Jay.fowke@ vanderbilt.edu.

Conflicts of Interest: none declared for all authors. 
Jay H. Fowke

Division of Epidemiology, Department of Medicine, Vanderbilt Epidemiology Center, VanderbiltIngram Cancer Center, Vanderbilt University School of Medicine, Nashville, USA

\section{Abstract}

Vitamin E includes several tocopherol isoforms which may reduce lung cancer risk, but past studies evaluating the association between vitamin $\mathrm{E}$ intake and lung cancer risk were inconsistent. We prospectively investigated the associations between tocopherol intake from diet and from supplements with lung cancer risk among 72,829 Chinese female nonsmokers aged 40-70 years and participating in the Shanghai Women's Health Study (SWHS). Dietary and supplement tocopherol exposure was assessed by a validated food-frequency questionnaire at baseline, and also reassessed for change in intake during follow-up. Cox proportional hazards models with time-dependent covariates were used to calculate multivariate-adjusted hazard ratios (HRs) and 95\% confidence interval (CIs) for lung cancer. After 12.02 years of follow-up, 481 women were diagnosed with lung cancer. Total dietary tocopherol was inversely associated with lung cancer risk among women meeting dietary guidelines for adequate intake (AI) of tocopherol ( $14 \mathrm{mg} /$ day or more: HR: 0.78 ; $95 \%$ CI 0.60-0.99; compared to the category less than AI). The protective association between dietary tocopherol intake and lung cancer was restricted to women exposed to side-stream smoke in the home and workplace $(\mathrm{HR}=0.53(0.29-0.97)$, $\mathrm{p}$-trend $=0.04)$. In contrast, vitamin E supplement use was associated with increased lung cancer risk (HR: 1.33; 95\% CI 1.01-1.73), more so for lung adenocarcinoma risk (HR: 1.79; 95\% CI 1.23-2.60). In summary, dietary tocopherol intake may reduce the risk of lung cancer among female nonsmokers, however supplements may increase lung adenocarcinoma risk and requires further investigation.

\section{Keywords}

diet; dietary supplements; lung neoplasm; prospective study; tocopherols; women

\section{INTRODUCTION}

Lung cancer is the leading cause of cancer mortality worldwide, with almost 1.4 million deaths per year. ${ }^{1}$ Cigarette smoking is the predominant cause, exposing the airways to carcinogens and reactive oxygen and other free radicals leading to DNA damage in critical tumor suppressor genes. ${ }^{2}$ However, there is a clear gender difference, with cigarette smoking accounting for $80 \%$ of the worldwide lung cancer burden in males but about $50 \%$ of the burden infemales. ${ }^{3}$

Vitamin E refers to a class of essential lipid-soluble antioxidants consisting of tocopherols and tocotrienols. As the major source of vitamin $\mathrm{E}$ in diet, tocopherols include four isoforms $(a, \beta, \gamma$, and $\delta$ ) differentiated by the number andposition of methyl groups on the chromanol ring. Tocopherols reduce nitrite and inhibit the production of carcinogenic nitrosoamines and nitrosoamides ${ }^{4-7}$ Additionally, tocopherols may inhibit carcinogenesis through inhibition of cell proliferation, ${ }^{8}$ induction of apoptosis, ${ }^{8}$ inhibition of angiogenesis, ${ }^{9}$ and enhancement of immune function. ${ }^{9}$ 
The relationship between dietary intake of tocopherols and lung cancer risk has been evaluated in several prospective studies, ${ }^{10-18}$ with the majority showing no significant association. The Alpha-Tocopherol, Beta-Carotene Cancer Prevention (ATBC) study, a randomized, placebo-controlled trial of male smokers, reported a statistically significant protective association between total dietary tocopherol and lung cancer, but no association between a-tocopherol supplement use and lung cancer risk. ${ }^{12,} 19$

The effects of tocopherols from diet and supplement use among female non-smokers are unclear. Non-smoking Asian women are among the non-smoking populations with the highest risk of lung cancer. ${ }^{20,21}$ Herein, we evaluate the relationship between tocopheral exposure and lung cancer risk in the Shanghai Women's Health Study (SWHS), a prospective cohort study where over $97 \%$ of participants were non-smokers. Our results may provide further insight into the risks and benefits of tocopherol intake toward lung cancer prevention among non-smoking women.

\section{METHODS}

\section{Study Population}

The Shanghai Women's Health Study (SWHS) is a population-based, prospective cohort study based in urban Shanghai, China. Details of the study design and methods of the SWHS have been published previously. ${ }^{22,23}$ Briefly, the SWHS recruited 74,942 females aged 40-70 years from 1997 to 2000. Participants resided in seven urban communities of Shanghai, and the response rate of $92.7 \%$.

At baseline, participants completed an in-person interview using a structured questionnaire to obtain information about demographic characteristics, lifestyle, dietary habits, medical history, occupational history, and physical activity. Anthropometrics, including weight, height, and circumferences of the waist and hip, were also measured at baseline. The survey also asked participants questions about smoking habits of their husband and people at work. Exposure was classified as low exposure (never exposed or exposed to the side-stream tobacco smoke in the home or work place) and high exposure (exposed to the side-stream smoke in the home and work place). All participants provided written informed consent. The SWHS was approved by the Institutional Review Boards for human research at all participating institutes.

Considering the low prevalence of smoking in this cohort ( $\mathrm{n}=2,113,2.8 \%)$, we decided to include only those women who never smoked $(n=72,829)$. Additional exclusions included: (1) a previous diagnosis of cancer before enrollment ( $n=1,527)$; (2) loss to follow-up shortly after enrollment ( $\mathrm{n}=5)$; (3) diagnosis of cancer in situ during follow-up ( $\mathrm{n}=67)$; (4) a cancer diagnosis that could not be confirmed $(\mathrm{n}=15)$; (5) death from cancer with no cancer type or diagnosis date $(\mathrm{n}=106)$; (6) extreme values for total energy intake ( $<500$ or $>4,000 \mathrm{kcal} / \mathrm{d}$ ) $(n=13)$; (7) or missing data for any of the covariates of interests $(n=6,030)$. After these exclusions, a total of 65,066 participants remained. 


\section{Assessment of Dietary Intake}

Dietary information was collected using a validated semi-quantitative food-frequency questionnaire (FFQ) at baseline and at first follow-up conducted 2-3 years after baseline. ${ }^{23}$ The FFQ included 77 food items encompassing about $90 \%$ of commonly consumed food items in urban Shanghai in $1996 .{ }^{23}$ The validity and reproducibility of the questionnaire used in the SWHS has been described. ${ }^{23}$ During the in-person interview, each participant was first asked how often, on average, she consumed a specific food or food group during the 12-month time period prior to the interview. Possible responses included: daily, weekly, monthly, yearly, or never. A follow-up question asked about the amount consumed in liang (1 liang=50g) per unit of time. Each participant was also asked about whether he or she had taken vitamin supplements (A, B, C, or E; a multivitamin; or calcium) at least 3 times per week continuously for more than 2 months. Our validation study showed that the validity of the FFQ was at least as good as that of the FFQ used in other major cohort studies. ${ }^{24}$ The correlation coefficient between Vitamin E estimated by FFQ compared to the means of the 24-hour dietary recalls (the recalls were conducted twice per month during a 12-month period) was $r=0.49 .{ }^{23}$ Although the correlation is typical when comparing FFQ to 24-hour diet recall assessment estimates ${ }^{23}$, we attempted to improve the assessment of usual dietary intake by FFQ in our analysis by averaging the intakes from the baseline FFQ and the FFQ completed 2-3 years after baseline which has recently become available for analysis from the SWHS. ${ }^{25}$ For persons who reported having diabetes or cardiovascular disease diagnosed between the two FFQ surveys, only baseline dietary intake was used as the exposure $(n=5,450,7.5 \%)$. Total energy and nutrient intakes for each food were calculated by multiplying the amount of food consumed by the energy or nutrient content per gram of the food, as obtained from the Chinese Food Composition Tables. ${ }^{26}$ Total dietary consumption of each nutrient was calculated by summing the nutrients from all food items reported in the FFQ.

\section{Follow-up and Cancer Identification}

Cohort members were followed for diagnosis of cancer by in-person follow-up surveys every 2-3 years, and annual record linkage with databases from the population-based Shanghai Cancer Registry, Shanghai Vital Statistics Registry, and Shanghai Resident Registry. The SWHS underwent four in-person follow-up surveys between 2000 and 2011 to ascertain changes in health status, with survey response rates for the first (2000-2002), second (2002-2004), third (2004-2007), and fourth (2008-2011) surveys were 99.8\%, $98.7 \%, 96.7 \%$, and $92.0 \%$, respectively. All possible cancer diagnoses were verified through home visits and a review of medical charts by a panel of oncologists. Lung cancer was defined under code 162 as per the International Classification of Disease $-9^{\text {th }}$ revision. Histological groups of lung cancer cases with sufficient sample size for analysis were classified as adenocarcinoma or non-adenocarcinoma according to the morphology code of International Classification of Diseases for Oncology-2 ${ }^{\text {nd }}$ edition (ICD-O-2, 8140/3).

\section{Statistical Analysis}

Dietary tocopherol was categorized into tertiles, with the lowest tertile of intake serving as the reference group. Tests for linear trend were performed by assigning an ordinal value ( 1 , 
2 , and 3) to each category and treating it as a continuous variable in the regression model. A second categorization of dietary tocopherol intake used the recommendation of the Chinese Nutrient Society, which advises an adequate intake (AI) of tocopherol for adults at 14 $\mathrm{mg}$ /day or more. ${ }^{27}$ Current vitamin E and multivitamin supplement use was categorized as Yes/No and treated as a time-dependent variable using a counting process approach to capture the changes in vitamin $\mathrm{E}$ and multivitamin supplement intakes during the follow-up period. ${ }^{28}$

Person-years of follow-up time were calculated for each participant from the date of the baseline interview to the date of cancer diagnosis, death, loss to follow-up, or December 31, 2010, whichever date occurred first. Cox proportional hazard regression models were used to estimate hazard ratios (HRs) and 95\% confidence intervals (CIs), with age as the time scale. The proportional hazards assumption was examined by evaluation of the interaction between exposure and survival time in the models, and we found no violations of the model assumptions.

We evaluated a range of possible subject characteristics, diet, and health status as potential confounders in the analysis. Final models included factors assessed at study recruitment: age (years, continuous); total energy intake (kcal/day, continuous); ever consumption of tea (yes or no); the average calcium-to-magnesium ( $\mathrm{Ca}: \mathrm{Mg}$ ) ratio intake (calculated as calcium divided by magnesium intake, continuous), ${ }^{29}, 30$ status exposure to passive smoking (low or high). Further adjustment for body mass index (BMI calculated as weight in $\mathrm{kg} / \mathrm{m}^{2}$, continuous); family income level (three categories: low [ $<5,000$ yuan/year], medium [5,000 to $<10,000$ yuan/year], and high [ $>10,000$ yuan/year]), education level (four categories: elementary school or less, middle school, high school, and college or above), leisure time exercises (calculated by metabolic equivalent (MET)-hours per week per year, continuous), menopause status (yes or no), red meat intake(continuous), alcohol intake (yes or no), isoflavone intake ( $\mathrm{mg} / \mathrm{day}$, continuous), and the ventilation condition of the kitchen did not alter our findings $(<10 \%$ change in tocopherol HR) and to maintain model stability therefore were not included in the final models.

All statistical analyses were performed using SAS software, version 9.3 (SAS Institute, Inc, Cary, NC). All $P$-values were calculated using two-sided tests and were considered statistically significant if $P$ was less than 0.05 .

\section{RESULTS}

During a mean follow-up period of 12.02 years, we identified 481 incident cases of cancer of the bronchus or lung. Table 1 presents age-adjusted study population characteristics by tertile of total dietary tocopherols. Higher total dietary tocopherol intake decreased significantly with older age. Additionally, dietary tocopherol intake was significantly associated with higher BMI, more physical exercise, education, occupational category, annual family income, as well as dietary factors such as energy, red meat, and isoflavone intakes. Furthermore, greater tocopherol intake was significantly higher among women likely exposed to second-hand tobacco smoke in the home or workplace. 
The associations of lung cancer with intake of tocopherol are presented in Table 2. Greater total dietary tocopherol and specific tocopherol isoforms intakes were associated with lower lung cancer risk in multivariable-adjusted models, though none of them reached statistical significance. The protective effect was stronger among women complying with suggested dietary guidelines for tocopherol intake (14 mg/day or more: HR: 0.73; 95\% CI 0.54-0.99; compared to the category less than $14 \mathrm{mg} /$ day). In contrast, use of vitamin E supplement was significantly associated with an increase in lung cancer risk (HR: 1.33 ; 95\% CI 1.01-1.73) (Table 2).

Dietary tocopherol intake was significantly associated with a lower lung cancer risk among women likely exposed to side-stream tobacco smoke in the home or workplace (HR: 0.53; 95\% CI 0.29-0.97 for the highest tertile compared to the lowest, p-trend $=0.04$ ) (Table 3).A similar pattern was observed among women complying with suggested dietary guidelines for tocopherol intake (Table 3).Use of vitamin E supplements, in contrast, was significantly associated with increased lung cancer risk among women likely exposed to side-stream tobacco smoke (HR=2.06 (95\% CI 1.31-3.23)).

We also conducted a joint analysis to see the effects of dietary tocopherol intake with and without vitamin E supplements. Greater tocopherol intake was generally protective for lung cancer among women who did not take a supplement, with marginally significant trend tests for total tocopherol and tocopherol sub-types ( $\beta$ and $\gamma$ and $\delta$-tocopherols) (Supplemental Table 1).There was a significant interaction between $\alpha$-tocopherol intake and taking vitamin E supplements on lung cancer risk ( $P$ interaction $=0.03$ ), but we did not see a clear pattern or trend. Alternatively, use of vitamin E supplements was associated with greater lung cancer risk regardless of whether they had an adequate tocopherol intake, although statistical significance was lost after stratification (Supplemental Table 2).

We evaluated the association between tocopherol exposure and lung cancer risk by histologic subtypes, including 217 adenocarcinomas and 69 non-adenocarcinomas (i.e., squamous cell and small-cell carcinomas, excludes 195 unclassified tumors) (Supplemental Table 3). Intake of total dietary tocopherol and specific tocopherol isoforms were not significantly associated with lung adenocarcinoma or non-adenocarcinoma risk. In contrast, vitamin E supplement use was significantly associated with an increased risk of lung adenocarcinoma (HR: 1.79; 95\% CI 1.23-2.60).

To minimize the potential influence of preclinical disease on our results, we excluded 45 cases diagnosed within two years of follow-up and found no appreciable change in the risk estimates. When we stratified by the median time interval between baseline and lung cancer diagnosis, the test for interaction with follow-up time did reach statistical significance (Supplemental Table 4). We also excluded the first three, four and five years of follow-up and found similar results with supplement use (Supplemental Table 5). Similarly, we assessed the effect of missing data from the second FFQ in a subset of participants by restricting the analysis to those participants whom completed both the first and second FFQ and were free of chronic disease and cancer at the second FFQ survey $(n=62,719)$. Again, the results were unchanged. 


\section{DISCUSSION}

Our analyses found that total dietary tocopherol intake was inversely associated with lung cancer risk among women complying with suggested dietary recommendations for tocopherol intake. In contrast, vitamin E supplement use was associated with a significant increase in lung cancer risk, specific to adenocarcinomas. In addition, dietary tocopherol intake was associated with lower lung cancer risk among women reporting exposure to sidestream tobacco smoke in the home and workplace. Vitamin E supplement use remained associated with increased lung cancer risk among these passive smokers.

The four tocopherol isoforms analyzed include the most biologically active isoforms and the major sources of vitamin $\mathrm{E}$ in diet, serving primarily as lipid soluble antioxidants. ${ }^{31}$ The association between dietary tocopherol and lung cancer risk has been investigated in several prior prospective studies ${ }^{10-18}$ but with conflicting results. Only two prior studies ${ }^{11,15}$ investigated the tocopherol and lung cancer relationship among women. Speizer et al. ${ }^{11}$ found no significant association between dietary and supplement vitamin E exposure (combined) with lung cancer (relative risk (RR): 1.2 ; 95\% CI 0.9-1.6; $P$ trend $=0.10$ ) while Bandera et al. ${ }^{15}$ reported a non-significant inverse association (RR: 0.8; 95\% CI 0.52-1.23; $P$ trend=0.28). Furthermore, Yong et al. ${ }^{13}$ found no association among non-smokers in an analysis that combined both genders (RR: $0.87 ; 95 \%$ CI 0.49-1.60; $P$ trend=0.33). In contrast, the protective association we see between total dietary tocopherol intake and lung cancer in women was consistent with an investigation from Woodson et al ${ }^{12}$ evaluating total dietary tocopherol at baseline with lung cancer risk among male smokers in the ATBC clinical trial.

a-Tocopherol is the most common isoform used in vitamin E supplement in the US and China. ${ }^{31,32}$ However, compared to $\alpha$-tocopherol, $\gamma$-tocopherol and $\delta$-tocopherol are more abundant in the diet and more effective in trapping reactive oxygen and nitrogen species due to the unmethylated carbon at the 5-position of the chromanol ring. ${ }^{31}$ Experimental studies also suggest that a-tocopherol is less able to induce apoptosis compared to $\gamma$ - and $\delta$ tocopherol. ${ }^{33}$ Differences in isoform metabolism may also be relevant ${ }^{34}$ if $\beta$ or $\gamma$-tocopherol levels in blood are lower than a-tocopherol levels and therefore have less hepatic toxicity. ${ }^{31}$ Animal studies also suggest that $\gamma$ - and $\delta$-tocopherol may be responsible for any protection against lung cancer, ${ }^{35,36}$ however results from four nested case-control studies ${ }^{37-40}$ looking at serum $\beta$ - or $\gamma$-tocopherol concentration and lung cancer have been inconclusive. We mutually controlled for these three isoforms in our multivariable models, but the direction and magnitude of risk estimates were similar to our reported results (data not shown) and we were unable to isolate a single dietary isoform protective for lung cancer risk.

Our study observed a positive association between vitamin E supplement use and lung cancer risk, especially with lung adenocarcinoma. Several randomized controlled trials and cohort studies 10, 41-44 have examined this association, but only two studies demonstrated the results among women. ${ }^{41,42}$ The Women's Health Study (WHS) found 600 international units (IU) of a-tocopherol every other day had no significant effect on the incidence of lung cancer (RR: $1.09 ; 95 \%$ CI $0.83-1.44 ; P=0.52$ ) ${ }^{42}$ In contrast, a prospective study in California reported a RR of 0.74 (95\% CI 0.46-1.18) for women comparing vitamin E 
supplement users to non-users. ${ }^{41}$ These two studies included both smoking and non-smoking women. ${ }^{41,42}$ It is possible that pharmacological doses of tocopherol found in supplements might affect cytochrome P450 enzyme activity or other regulatory mechanisms, ${ }^{45}$ or that $\mathrm{a}$ tocopherol from supplements interact with other tocopherols in blood to induce an effect. ${ }^{45,46}$ Adenocarcinomas are the common form of lung cancer in non-smokers, ${ }^{20}$ and further research is needed to understand why vitamin E supplement use may increase lung adenocarcinoma risk in non-smokers.

As exposure to side-stream smoking may increase oxidative stress, ${ }^{47,48}$ we carried-out a stratified analysis of tocopherols and lung cancer risk by passive smoking status. There was a significant protective trend of total dietary tocopherol intake among women highly exposed to side-stream smoke in the home and workplace, though the interaction was not statistically significant. Furthermore, vitamin E supplement significantly increased lung cancer risk among women most likely exposed to side-stream tobacco smoke. Confirmation of these novel results may suggest that dietary tocopherol, rather than supplements, is a more beneficial prevention approach for non-smoking women who live or work where smoking is prevalent.

Strengths of our investigation include a population-based prospective design, and a large sample of female non-smokers. Baseline and follow-up participation rates were exceptionally high, with repeated dietary assessments with a validated FFQ minimized measurement error or selection bias. We controlled for multiple potential confounders, including isoflavone intake and passive smoke exposure in home or workplace, kitchen ventilation, and other supplement use. Furthermore, we carried out several sensitivity analyses that excluded potential preclinical lung cancer in the first 2 years of follow-up or dietary misclassification due to missing follow-up FFQ, and found no impact on the results.

Limitations of this study also should be addressed. Vitamin E supplement capsules on the market in Shanghai vary from $20 \%$ to $39 \%$ in the proportion of a -tocopherols, with capsule weight varying from $250 \mathrm{mg}$ to $500 \mathrm{mg}$, The FFQ did not assess the dose provided by vitamin supplements, thus vitamin supplement use was analyzed as a categorical variable (yes or no) and we could not evaluate vitamin E supplement dose-response effects with lung cancer risk. ${ }^{49}$ Also, tocopherol from cooking oil or other non-diet sources were not measured. However, the FFQ has reasonably good correlation with data from repeated 24-hour dietary recalls (tocopherol $r=0.49)^{23}$, and dietary assessment error in this prospective cohort would likely be non-differential with respect to lung cancer. Thus, if anything, this error would lead to an attenuation of the true association. We had limited statistical power to investigate lung non-adenocarcinoma risk, and an expanded analysis by histology subtype should be conducted in future studies.

In summary, in this population-based prospective study, we found that greater total dietary tocopherol over the AI (14mg/day) was significantly associated with lower lung cancer risk. In contrast, vitamin E supplement use was associated with increased lung cancer risk, especially for lung adenocarcinoma or with exposure to passive smoking. The reason for differences between dietary and supplement tocopherol exposure on lung cancer requires further investigation. 


\section{Supplementary Material}

Refer to Web version on PubMed Central for supplementary material.

\section{Acknowledgments}

This work was supported by grants from the United States National Institutes of Health (R37 CA070867, R01 CA82729 and R01 HL095931) and the funding of State Key Project Specialized for Infectious Diseases of China (No. 2008ZX10002-015 and 2012ZX10002008-002).

We would like to thank the participants and the staff of the Shanghai Women's Health Study for their contribution to this research. We also thank Dr. Qi Dai for assistance in the interpretation of the results of this manuscript.

\section{References}

1. Jemal A, Bray F, Center MM, Ferlay J, Ward E, Forman D. Global cancer statistics. CA Cancer J Clin. 2011; 61:69-90. [PubMed: 21296855]

2. Hirao T, Nelson HH, Ashok TD, Wain JC, Mark EJ, Christiani DC, Wiencke JK, Kelsey KT. Tobacco smoke-induced DNA damage and an early age of smoking initiation induce chromosome loss at 3p21 in lung cancer. Cancer Res. 2001; 61:612-5. [PubMed: 11212258]

3. Ezzati M, Lopez AD. Estimates of global mortality attributable to smoking in 2000. Lancet. 2003; 362:847-52. [PubMed: 13678970]

4. Ames BN. Dietary carcinogens and anticarcinogens. Oxygen radicals and degenerative diseases. Science. 1983; 221:1256-64. [PubMed: 6351251]

5. Machlin LJ, Bendich A. Free radical tissue damage: protective role of antioxidant nutrients. Faseb J. 1987; 1:441-5. [PubMed: 3315807]

6. Stone WL, Papas AM. Tocopherols and the etiology of colon cancer. J Natl Cancer Inst. 1997; 89:1006-14. [PubMed: 9230882]

7. Knekt P. Role of vitamin E in the prophylaxis of cancer. Ann Med. 1991; 23:3-12. [PubMed: 2036202]

8. Sigounas G, Anagnostou A, Steiner M. dl-alpha-tocopherol induces apoptosis in erythroleukemia, prostate, and breast cancer cells. Nutr Cancer. 1997; 28:30-5. [PubMed: 9200147]

9. Shklar G, Schwartz JL. Vitamin E inhibits experimental carcinogenesis and tumour angiogenesis. Eur J Cancer B Oral Oncol. 1996; 32B:114-9. [PubMed: 8736173]

10. Voorrips LE, Goldbohm RA, Brants HA, van Poppel GA, Sturmans F, Hermus RJ, van den Brandt PA. A prospective cohort study on antioxidant and folate intake and male lung cancer risk. Cancer Epidemiol Biomarkers Prev. 2000; 9:357-65. [PubMed: 10794479]

11. Speizer FE, Colditz GA, Hunter DJ, Rosner B, Hennekens C. Prospective study of smoking, antioxidant intake, and lung cancer in middle-aged women (USA). Cancer Causes Control. 1999; 10:475-82. [PubMed: 10530619]

12. Woodson K, Tangrea JA, Barrett MJ, Virtamo J, Taylor PR, Albanes D. Serum alpha-tocopherol and subsequent risk of lung cancer among male smokers. J Natl Cancer Inst. 1999; 91:1738-43. [PubMed: 10528024]

13. Yong LC, Brown CC, Schatzkin A, Dresser CM, Slesinski MJ, Cox CS, Taylor PR, First National Health and Nutrition Examination Survey. Intake of vitamins E, C, and A and risk of lung cancer. The NHANES I epidemiologic followup study. Am J Epidemiol. 1997; 146:231-43. [PubMed: 9247007]

14. Ocke MC, Bueno-de-Mesquita HB, Feskens EJ, van Staveren WA, Kromhout D. Repeated measurements of vegetables, fruits, beta-carotene, and vitamins $\mathrm{C}$ and $\mathrm{E}$ in relation to lung cancer. The Zutphen Study. Am J Epidemiol. 1997; 145:358-65. [PubMed: 9054240]

15. Bandera EV, Freudenheim JL, Marshall JR, Zielezny M, Priore RL, Brasure J, Baptiste M, Graham S. Diet and alcohol consumption and lung cancer risk in the New York State Cohort (United States). Cancer Causes Control. 1997; 8:828-40. [PubMed: 9427425] 
16. Knekt P. Vitamin E and smoking and the risk of lung cancer. Ann N Y Acad Sci. 1993; 686:280-7. 287-8. [PubMed: 8512253]

17. Connett JE, Kuller LH, Kjelsberg MO, Polk BF, Collins G, Rider A, Hulley SB. Relationship between carotenoids and cancer. The Multiple Risk Factor Intervention Trial (MRFIT) Study. Cancer. 1989; 64:126-34. [PubMed: 2731108]

18. Yuan JM, Stram DO, Arakawa K, Lee HP, Yu MC. Dietary cryptoxanthin and reduced risk of lung cancer: the Singapore Chinese Health Study. Cancer Epidemiol Biomarkers Prev. 2003; 12:890-8. [PubMed: 14504200]

19. The Alpha-Tocopherol, Beta Carotene Cancer Prevention Study Group. The effect of vitamin E and beta carotene on the incidence of lung cancer and other cancers in male smokers. N Engl J Med. 1994; 330:1029-35. [PubMed: 8127329]

20. Sun S, Schiller JH, Gazdar AF. Lung cancer in never smokers--a different disease. Nat Rev Cancer. 2007; 7:778-90. [PubMed: 17882278]

21. Chen JG, Zhu J, Parkin DM, Zhang YH, Lu JH, Zhu YR, Chen TY. Trends in the incidence of cancer in Qidong, China, 1978-2002. Int J Cancer. 2006; 119:1447-54. [PubMed: 16596645]

22. Zheng W, Chow WH, Yang G, Jin F, Rothman N, Blair A, Li HL, Wen W, Ji BT, Li Q, Shu XO, Gao YT. The Shanghai Women's Health Study: rationale, study design, and baseline characteristics. Am J Epidemiol. 2005; 162:1123-31. [PubMed: 16236996]

23. Shu XO, Yang G, Jin F, Liu D, Kushi L, Wen W, Gao YT, Zheng W. Validity and reproducibility of the food frequency questionnaire used in the Shanghai Women's Health Study. Eur J Clin Nutr. 2004; 58:17-23. [PubMed: 14679362]

24. Yang G, Shu XO, Li HL, Chow WH, Wen W, Xiang YB, Zhang X, Cai H, Ji BT, Gao YT, Zheng W. Prediagnosis soy food consumption and lung cancer survival in women. J Clin Oncol. 2013; 31:1548-53. [PubMed: 23530109]

25. Wu QJ, Xie L, Zheng W, Vogtmann E, Li HL, Yang G, Ji BT, Gao YT, Shu XO, Xiang YB. Cruciferous vegetables consumption and the risk of female lung cancer: a prospective study and a meta-analysis. Ann Oncol. 2013; 24:1918-24. [PubMed: 23553059]

26. Yang, G.; Wang, G.; Pan, X. Chinese Food Composition Tablesed. Peking University Medical Press; Beijing, China: 2002.

27. Chinese Nutrition Socity. [accessed 1 July 2013] Dietary Reference Intakes. Internet: http:// www.cnsoc.org/cn/disciplinary.asp?s=4\&nid=23

28. Hosmer, DW., Jr; Lemeshow, S. Applied Survival Analysis: RegressionModeling of Time to Event Data. John Wiley \& Sons Inc; New York, NY: 1999.

29. Takata Y, Shu XO, Yang G, Li H, Dai Q, Gao J, Cai Q, Gao YT, Zheng W. Calcium intake and lung cancer risk among female nonsmokers: a report from the Shanghai Women's Health Study. Cancer Epidemiol Biomarkers Prev. 2013; 22:50-7. [PubMed: 23093548]

30. Dai Q, Shu XO, Deng X, Xiang YB, Li H, Yang G, Shrubsole MJ, Ji B, Cai H, Chow WH, Gao YT, Zheng W. Modifying effect of calcium/magnesium intake ratio and mortality: a populationbased cohort study. BMJ Open. 2013; 3

31. Yang CS, Suh N, Kong AN. Does vitamin E prevent or promote cancer? Cancer Prev Res (Phila). 2012; 5:701-5. [PubMed: 22490437]

32. ZheJiang Medicine Co.. [accessed 22 Janurary 2014] Vitamin E Soft Capsules. Internet: http:// www.china-zmc.com/index.php?c=article \& column $=4 \& \mathrm{id}=26$

33. Constantinou C, Papas A, Constantinou AI. Vitamin E and cancer: An insight into the anticancer activities of vitamin E isomers and analogs. Int J Cancer. 2008; 123:739-52. [PubMed: 18512238]

34. Traber, MG.; Vitamin, E. Present knowledge in nutrition. 9th ed.. Bowman, BA.; Russell, RM., editors. ILSI Press; Washington DC: 2006. p. 211-9.

35. Li GX, Lee MJ, Liu AB, Yang Z, Lin Y, Shih WJ, Yang CS. delta-tocopherol is more active than alpha - or gamma -tocopherol in inhibiting lung tumorigenesis in vivo. Cancer Prev Res (Phila). 2011; 4:404-13. [PubMed: 21372040]

36. Lu G, Xiao H, Li GX, Picinich SC, Chen YK, Liu A, Lee MJ, Loy S, Yang CS. A gammatocopherol-rich mixture of tocopherols inhibits chemically induced lung tumorigenesis in A/J mice and xenograft tumor growth. Carcinogenesis. 2010; 31:687-94. [PubMed: 20097733] 
37. Ito Y, Wakai K, Suzuki K, Tamakoshi A, Seki N, Ando M, Nishino Y, Kondo T, Watanabe Y, Ozasa K, Ohno Y. Serum carotenoids and mortality from lung cancer: a case-control study nested in the Japan Collaborative Cohort (JACC) study. Cancer Sci. 2003; 94:57-63. [PubMed: 12708475]

38. Goodman GE, Schaffer S, Omenn GS, Chen C, King I. The association between lung and prostate cancer risk, and serum micronutrients: results and lessons learned from beta-carotene and retinol efficacy trial. Cancer Epidemiol Biomarkers Prev. 2003; 12:518-26. [PubMed: 12814997]

39. Ratnasinghe DL, Yao SX, Forman M, Qiao YL, Andersen MR, Giffen CA, Erozan Y, Tockman MS, Taylor PR. Gene-environment interactions between the codon 194 polymorphism of XRCC1 and antioxidants influence lung cancer risk. Anticancer Res. 2003; 23:627-32. [PubMed: 12680158]

40. Yuan JM, Ross RK, Chu XD, Gao YT, Yu MC. Prediagnostic levels of serum beta-cryptoxanthin and retinol predict smoking-related lung cancer risk in Shanghai, China. Cancer Epidemiol Biomarkers Prev. 2001; 10:767-73. [PubMed: 11440962]

41. Shibata A, Paganini-Hill A, Ross RK, Henderson BE. Intake of vegetables, fruits, beta-carotene, vitamin $C$ and vitamin supplements and cancer incidence among the elderly: a prospective study. Br J Cancer. 1992; 66:673-9. [PubMed: 1419605]

42. Lee IM, Cook NR, Gaziano JM, Gordon D, Ridker PM, Manson JE, Hennekens CH, Buring JE. Vitamin $\mathrm{E}$ in the primary prevention of cardiovascular disease and cancer: the Women's Health Study: a randomized controlled trial. JAMA. 2005; 294:56-65. [PubMed: 15998891]

43. Lonn E, Bosch J, Yusuf S, Sheridan P, Pogue J, Arnold JM, Ross C, Arnold A, Sleight P, Probstfield J, Dagenais GR. Effects of long-term vitamin E supplementation on cardiovascular events and cancer: a randomized controlled trial. JAMA. 2005; 293:1338-47. [PubMed: 15769967]

44. Virtamo J, Pietinen P, Huttunen JK, Korhonen P, Malila N, Virtanen MJ, Albanes D, Taylor PR, Albert P. Incidence of cancer and mortality following alpha-tocopherol and beta-carotene supplementation: a postintervention follow-up. JAMA. 2003; 290:476-85. [PubMed: 12876090]

45. Lippman SM, Klein EA, Goodman PJ, Lucia MS, Thompson IM, Ford LG, Parnes HL, Minasian LM, Gaziano JM, Hartline JA, Parsons JK, Bearden JR, et al. Effect of selenium and vitamin E on risk of prostate cancer and other cancers: the Selenium and Vitamin E Cancer Prevention Trial (SELECT). JAMA. 2009; 301:39-51. [PubMed: 19066370]

46. Lippman SM, Goodman PJ, Klein EA, Parnes HL, Thompson IJ, Kristal AR, Santella RM, Probstfield JL, Moinpour CM, Albanes D, Taylor PR, Minasian LM, et al. Designing the Selenium and Vitamin E Cancer Prevention Trial (SELECT). J Natl Cancer Inst. 2005; 97:94-102. [PubMed: 15657339]

47. Mahabir S, Schendel K, Dong YQ, Barrera SL, Spitz MR, Forman MR. Dietary alpha-, beta-, gamma- and delta-tocopherols in lung cancer risk. Int J Cancer. 2008; 123:1173-80. [PubMed: 18546288]

48. Ju J, Picinich SC, Yang Z, Zhao Y, Suh N, Kong AN, Yang CS. Cancer-preventive activities of tocopherols and tocotrienols. Carcinogenesis. 2010; 31:533-42. [PubMed: 19748925]

49. Zhang W, Shu XO, Li H, Yang G, Cai H, Ji BT, Gao J, Gao YT, Zheng W, Xiang YB. Vitamin intake and liver cancer risk: a report from two cohort studies in China. J Natl Cancer Inst. 2012; 104:1173-81. [PubMed: 22811438] 


\section{Brief description of the novelty and impact}

Vitamin E may reduce lung cancer risk among non-smokers, but results from prior studies of vitamin $\mathrm{E}$ and lung cancer were inconsistent. The authors prospectively investigated the association between vitamin $\mathrm{E}$ intake and lung cancer among 72,829 female non-smokers. While dietary vitamin $\mathrm{E}$ intake was significantly associated with lower lung cancer risk, vitamin E supplementation was significantly associated with increased lung cancer risk suggesting caution if recommending vitamin $\mathrm{E}$ supplements to prevent lung cancer among non-smoking women. 


\section{TABLE 1}

Study population characteristics according to total dietary tocopherol intake, Shanghai Women's Health Study (1997-2010)

\begin{tabular}{|c|c|c|c|c|}
\hline \multirow{2}{*}{ Characteristic } & \multicolumn{3}{|c|}{ Tertiles of total tocopherol intake (mg/day) } & \multirow[b]{2}{*}{$P$} \\
\hline & T1 $(<11.01)$ & T2 (11.01-14.87) & $\mathrm{T3}(\mathbf{1 4 . 8 7})$ & \\
\hline No. of participants & 21688 & 21689 & 21689 & \\
\hline No. of lung cancer cases & 200 & 152 & 129 & \\
\hline Age at recruitment (SD), year & $53.62(9.61)$ & $51.90(8.79)$ & $51.56(8.33)$ & $<0.01$ \\
\hline \multicolumn{5}{|l|}{ Mean (SE) } \\
\hline Body mass index, $\mathrm{kg} / \mathrm{m}^{2}$ & $23.87(0.02)$ & $23.93(0.02)$ & $24.29(0.02)$ & $<0.01$ \\
\hline Leisure time exercise, MET-h/w/y ${ }^{\dagger}$ & $12.19(0.18)$ & $13.05(0.16)$ & $14.97(0.15)$ & $<0.01$ \\
\hline Age at menopause, yeart & $48.38(0.04)$ & $48.67(0.04)$ & $48.83(0.04)$ & $<0.01$ \\
\hline Total energy intake, $\mathrm{kcal} / \mathrm{day}$ & $1409.35(1.90)$ & $1628.51(1.89)$ & $1892.19(1.89)$ & $<0.01$ \\
\hline Red meat intake * & $26.43(0.10)$ & $28.87(0.10)$ & $29.94(0.10)$ & $<0.01$ \\
\hline Isoflavone intake * & $12.72(0.06)$ & $18.51(0.06)$ & $26.13(0.06)$ & $<0.01$ \\
\hline Calcium:Magnesium ratio $*$ & $1.59(0.00)$ & $1.76(0.00)$ & $1.89(0.00)$ & $<0.01$ \\
\hline \multicolumn{5}{|l|}{ No. $(\%)$} \\
\hline Vitamin E supplement use (ever) & $4099(19.08)$ & $5264(24.32)$ & $6070(28.02)$ & $<0.01$ \\
\hline Multivitamin supplement use (ever) & $3296(15.35)$ & $4247(19.63)$ & $4814(22.18)$ & $<0.01$ \\
\hline Occupation & & & & $<0.01$ \\
\hline Housewife & $118(0.46)$ & $50(0.24)$ & $42(0.22)$ & \\
\hline Professional workers & $5156(24.69)$ & $6495(29.96)$ & $6791(31.03)$ & \\
\hline Clerical workers & $4457(20.89)$ & $4447(20.34)$ & $4537(20.69)$ & \\
\hline Manual workers & 11957 (53.97) & $10697(49.45)$ & $10319(48.06)$ & \\
\hline Education level & & & & $<0.01$ \\
\hline Elementary school or less & $6415(25.05)$ & $3849(18.88)$ & $3147(16.88)$ & \\
\hline Middle school & $7978(39.21)$ & $8446(38.21)$ & $8462(37.90)$ & \\
\hline High school & $5094(25.07)$ & $6354(28.90)$ & $6837(30.50)$ & \\
\hline College or above & $2201(10.67)$ & $3040(14.01)$ & $3243(14.72)$ & \\
\hline Family income, person/year & & & & $<0.01$ \\
\hline Low $(<5000)$ & $7243(31.71)$ & $5497(25.78)$ & $4975(23.98)$ & \\
\hline Middle (5000-10000) & $8583(39.69)$ & $8630(39.81)$ & $8451(39.29)$ & \\
\hline High ( $\geq 10000)$ & $5862(28.61)$ & $7562(34.41)$ & $8263(36.73)$ & \\
\hline Passive smoking $\S$ & & & & $<0.01$ \\
\hline Low & $15704(70.88)$ & $14899(69.16)$ & $14641(68.42)$ & \\
\hline High & $5984(29.12)$ & $6790(30.84)$ & $7048(31.58)$ & \\
\hline Ventilation condition of kitchen & & & & 0.95 \\
\hline Good & $21012(96.88)$ & $21020(96.92)$ & $21018(96.93)$ & \\
\hline Poor & $674(3.12)$ & $669(3.08)$ & $671(3.07)$ & \\
\hline Alcohol drinking (ever) & $384(1.72)$ & $394(1.82)$ & $485(2.26)$ & $<0.01$ \\
\hline Tea drinking (ever) & $5108(24.42)$ & $6567(29.99)$ & $7413(33.55)$ & $<0.01$ \\
\hline
\end{tabular}




\begin{tabular}{lcccc}
\hline \multirow{2}{*}{ Characteristic } & \multicolumn{3}{c}{ Tertiles of total tocopherol intake (mg/day) } & \\
\cline { 2 - 4 } & T1 (<11.01) & T2 (11.01-14.87) & T3( $\mathbf{1 4 . 8 7 )}$ & $\boldsymbol{P}$ \\
\hline Family history of lung cancer (ever) & $1002(4.75)$ & $1055(4.84)$ & $1141(5.20)$ & 0.09 \\
History of lung disease (ever) $\mathscr{I}$ & $2807(12.43)$ & $2922(13.71)$ & $2895(13.75)$ & $<0.01$ \\
Post-menopausal status & $11513(48.28)$ & $10084(48.43)$ & $9902(48.52)$ & 0.69 \\
\hline
\end{tabular}

All means, standard errors, or percentages for each characteristic (except age) were adjusted for age at baseline.

${ }^{\dagger}$ Leisure time exercise: metabolic equivalent (MET)-hours per week per year.

*Among postmenopausal women $(\mathrm{n}=33,939)$.

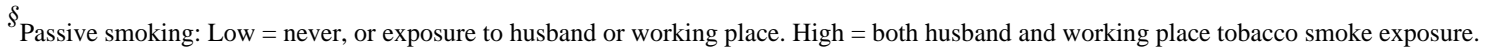

${ }^{\text {II }}$ Lung disease includes asthma, tuberculosis, and chronic bronchitis.

* Consumption of selected foods and nutrients were adjusted for energy intake using the nutrient density method. Foods expressed as per gram per 1000 kcal per day. 
TABLE 2

Hazard ratios for female lung cancer associated with tocopherol intake from diet or supplements, Shanghai Women's Health Study (1997-2010)

\begin{tabular}{|c|c|c|c|c|}
\hline Dietary intake (mg/day) & Range & Cases & Person years & $\begin{array}{c}\text { Multivariate HR (95\% } \\
\text { CI) }\end{array}$ \\
\hline \multicolumn{5}{|l|}{ Total Tocopherol ${ }^{\dagger}$} \\
\hline $\mathrm{T} 1$ & $<11.01$ & 200 & 259208 & 1.00 (ref) \\
\hline $\mathrm{T} 2$ & $11.01-14.87$ & 152 & 261464 & $0.87(0.68-1.11)$ \\
\hline $\mathrm{T} 3$ & $\geq 14.87$ & 129 & 261352 & $0.78(0.58-1.07)$ \\
\hline$P$ for trend & & & & 0.12 \\
\hline \multicolumn{5}{|l|}{ Total Tocopherol ${ }^{\dagger}$} \\
\hline$<\mathrm{AI}$ & $<14.00$ & 330 & 468142 & 1.00 (ref) \\
\hline $\mathrm{AI}$ or more & $\geq 14.00$ & 151 & 313882 & $0.78(0.60-0.99)$ \\
\hline \multicolumn{5}{|l|}{ a-tocopherol ${ }^{\dagger}$} \\
\hline $\mathrm{T} 1$ & $<3.39$ & 210 & 258185 & 1.00 (ref) \\
\hline $\mathrm{T} 2$ & $3.39-4.66$ & 142 & 261443 & $0.87(0.68-1.12)$ \\
\hline $\mathrm{T} 3$ & $\geq 4.66$ & 129 & 262395 & $0.90(0.66-1.24)$ \\
\hline$P$ for trend & & & & 0.47 \\
\hline \multicolumn{5}{|l|}{$\beta$ and $\gamma$-tocopherol ${ }^{\dagger}$} \\
\hline $\mathrm{T} 1$ & $<3.35$ & 193 & 259630 & 1.00 (ref) \\
\hline $\mathrm{T} 2$ & $3.35-4.89$ & 155 & 261355 & $0.93(0.73-1.18)$ \\
\hline $\mathrm{T} 3$ & $\geq 4.89$ & 133 & 261039 & $0.79(0.59-1.06)$ \\
\hline$P$ for trend & & & & 0.13 \\
\hline \multicolumn{5}{|l|}{$\delta$-tocopherol ${ }^{\dagger}$} \\
\hline $\mathrm{T} 1$ & $<2.86$ & 197 & 260041 & 1.00 (ref) \\
\hline $\mathrm{T} 2$ & $2.86-4.23$ & 147 & 261410 & $0.83(0.65-1.06)$ \\
\hline $\mathrm{T} 3$ & $\geq 4.23$ & 137 & 260573 & $0.78(0.59-1.04)$ \\
\hline$P$ for trend & & & & 0.08 \\
\hline \multicolumn{5}{|l|}{ Vitamin E supplements $\neq$} \\
\hline No & & 313 & 595711 & 1.00 (ref) \\
\hline Yes & & 168 & 186312 & $1.33(1.01-1.73)$ \\
\hline \multicolumn{5}{|l|}{ Multivitamin supplements $*$} \\
\hline No & & 337 & 632861 & 1.00 (ref) \\
\hline Yes & & 144 & 149163 & $1.17(0.89-1.53)$ \\
\hline
\end{tabular}

$\mathrm{AI}=$ adequate intake, $\mathrm{HR}=$ hazard ratios, $95 \% \mathrm{CI}=95 \%$ confidence intervals

${ }^{\dagger}$ Adjusted for age, average intake of total energy and the calcium-to-magnesium (Ca: $\mathrm{Mg}$ ) ratio, ever consumption of tea, status exposed to passive smoking, and ever use of vitamin E and multivitamin supplements.

${ }^{\ddagger}$ Further adjusted for total dietary tocopherol and vitamin supplements use (A, B, C, calcium, and other). 
TABLE 3

Effects of dietary tocopherol on lung cancer risk, by passive smoking status, Shanghai Women's Health Study (1997-2010)

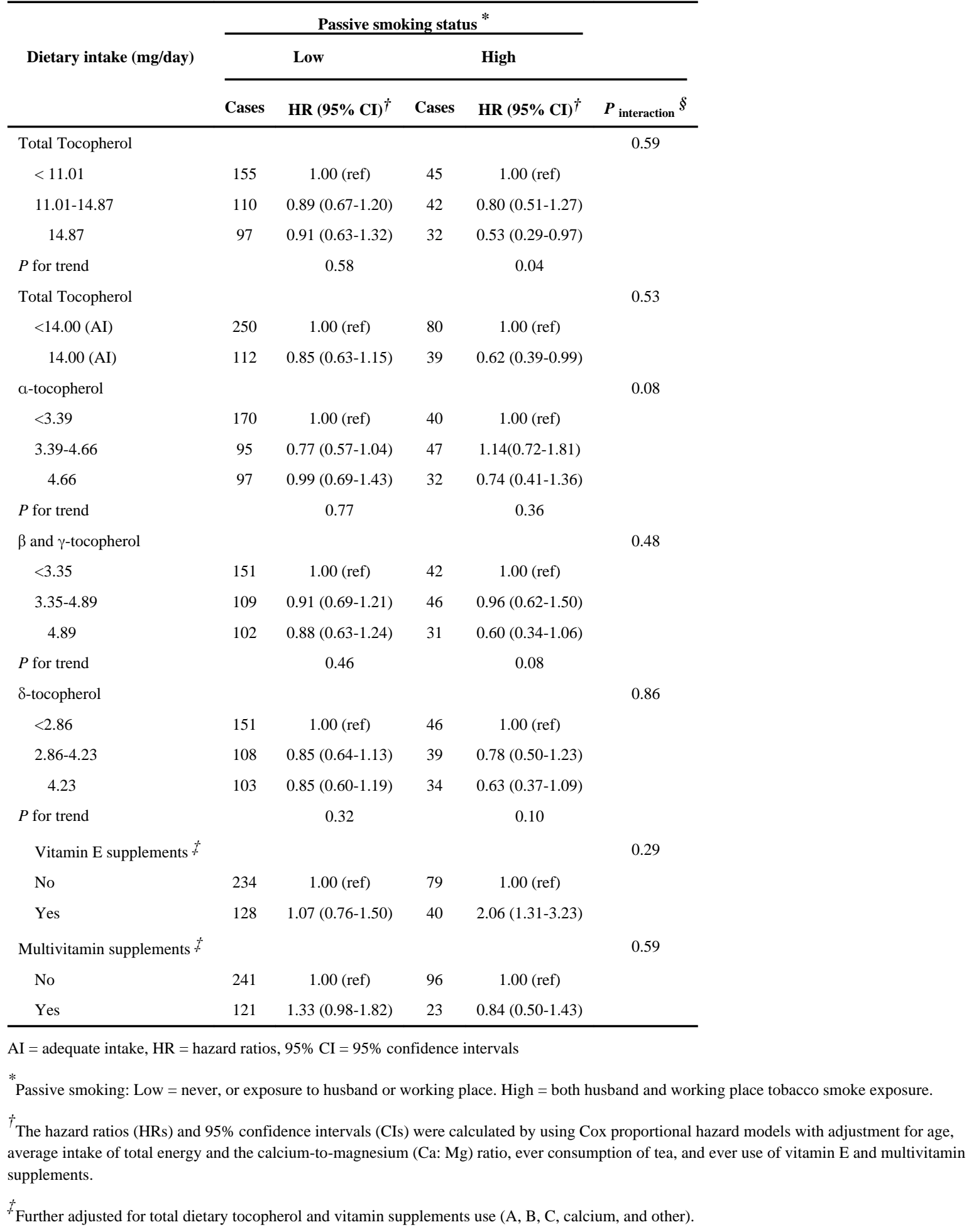


$\S_{P_{\text {interaction }} \text { was calculated by introducing an interaction term between the exposures and the status exposed to passive smoking in the regression }}$ model. 